\title{
Coronavirus disease 2019: A new severe acute respiratory syndrome from Wuhan in China
}

\author{
Y. CAO ${ }^{1,2 \#}$, K. CAI ${ }^{1,2 \#}$, L. XIONG ${ }^{2 *}$ \\ ${ }^{1}$ Department of Gastrointestinal Surgery, Union Hospital, Tongji Medical College, Huazhong University of Science and \\ Technology, Wuhan 430022, P. R. China; ${ }^{2}$ Department of Nosocomial Infection Management, Union Hospital, Tongji Medical \\ College, Huazhong University of Science and Technology, Wuhan, 430022, P. R. China
}

Received March 6, 2020; accepted March 25, 2020

\begin{abstract}
Summary. - An outbreak of new severe acute respiratory syndrome coronavirus disease, coronavirus disease 2019 (COVID-19), has emerged during December 2019. The ongoing outbreak in Wuhan City spread rapidly throughout China, where the fatality rate ranged from 2.1 to $4.9 \%$. Due to its high transmissibility, the World Health Organization (WHO) declared a public health emergency of international concern on 30 January 2020. The current outbreak has the potential to become the first pandemic of the new millennium. Most patients who were first diagnosed with COVID-19 worked at or lived in the vicinity of the local Huanan Seafood Wholesale Market, where live animals were also on sale. The concerted efforts of Chinese scientists led to the independent isolation from patients and identification of a novel coronavirus, SARS coronavirus 2 (SARS-CoV-2), on 6 January 2020; this has been an important step in the development of treatment. The purpose of this article is to overview the history, epidemiology, clinical characteristics, diagnosis, and treatment of COVID 2019 reported in recently published studies. Based on the results of virus genome sequencing and a model of the interaction between host cells and the virus, we propose several possible targets for antiviral drugs, which may provide new ideas for epidemic control and vaccine development.
\end{abstract}

Keywords: 2019 novel coronavirus; pneumonia; SARS-CoV-2; Coronaviridae; COVID-19

\section{Introduction}

The first reports of the current outbreak of the new coronavirus disease (COVID-19) during early December 2019 were from Wuhan, China (Huang et al., 2020). With the spread of the epidemic, there were cases reported in 27 countries and 5 continents, and more than 60,000 infected people as of 10 February 2020, and more than 75,000 infected people as of 25 February 2020 . The rapid

"Corresponding author. E-mail: 993964218@qq.com; phone: +8613971086426 . "These authors contributed equally to this work.

Abbreviations: COVID-19 = coronavirus disease 2019; SARSCoV-2 = SARS coronavirus 2; WHO = World Health Organization spread of the virus led to disease outbreaks worldwide, and the World Health Organization (WHO) declared a Public Health Emergency of International Concern on 30 January 2020 (WHO; Zhu et al.,2020). Many countries have declared states of emergency and evacuated their citizens from China. China initiated a first-level response to major public health emergencies in response to the epidemic.

China promptly released relevant information on measures to be used for prevention and control of the epidemic, and provided epidemiological data to the WHO and relevant countries and regions. The WHO website regularly provides the numbers of daily new cases. At present, people in the general population have limited knowledge about the virus, and no effective therapies are available. The number of infections continues to increase and the epidemic is now very serious. 
Table 1. Recent viral epidemics associated with high mortality

\begin{tabular}{llll}
\hline Year & Disease & Virus Family & Location \\
\hline 2003 & Severe acute respiratory syndrome & Coronaviridae & Worldwide \\
2009 & H1N1 swine flu & Orthomyxoviridae & Worldwide \\
2013 & H7N9 bird flu & Orthomyxoviridae & China \\
2014 & Ebola & Filoviridae & West Africa \\
2014 & Polio & Picornaviridae & Worldwide \\
2015 & Middle East respiratory syndrome & Coronaviridae & Middle East \\
2016 & Zika & Flaviviridae & Brazil \\
2019 & Ebola & Filoviridae & Congo \\
\hline
\end{tabular}

\section{History}

There were several serious human viral epidemics during the past 20 years (Table 1), and most of the infectious agents originated from poultry or wild animals. Gene sequencing indicated that the new coronavirus from Wuhan (SARS-CoV-2) belongs to the family Coronaviridae, the subgenus Sarbecovirus. Compared with SARS-CoV (identified in 2003), SARS-CoV-2 is more similar to two bat-derived coronavirus strains, SL-CoVZC45 and SL-CoVZXC21 (Lu et al., 2020). Ji et al. (2020) believe that SARS-CoV-2 has a codon preference similar to that of snakes, rather than other animals such as hedgehogs and pangolins, and that snakes are the most likely carriers of this novel coronavirus. Huaiqiu Zhu's team at the Peking University School of Technology used a viral host prediction (VHP) method based on deep learning algorithms and speculated that bats and minks were the two potential hosts for this new coronavirus, and that minks might function as intermediate hosts for virus transmission (Guo et al., 2020). Researchers at the Indian Institute of Technology suggested that the new coronavirus may be man-made (Pradhan et al., 2020), but most scientists reject this assertion. The latest research by Zhou et al. at the Wuhan Institute of Viruses suggests that bats are a possible source of the new coronavirus (Zhou et al., 2020). The results of Nanshan Zhong's team support this conclusion, but whether the virus needs an intermediate host requires further study (Zhou et al., 2020). Thus, the animal source of SARS-CoV-2 remains to be determined.

\section{Distribution and spread}

As of February 25, 2020, there were COVID-19 cases in 35 countries, with 67,120 confirmed infections and 1526 deaths. China accounted for $99.22 \%$ of infections and 99.87\% of deaths (Fig. 1). Hubei province, the epicenter of the epidemic, had $81.69 \%$ of the reported cases. Since the WHO declared COVID-19 to be a Public Health Emergency of International Concern, governments took aggressive action, and the number of new diagnoses in many countries has been declining. In China, however, the situation remains disturbingly out of control due to the massive population movement during the Chinese New Year. As
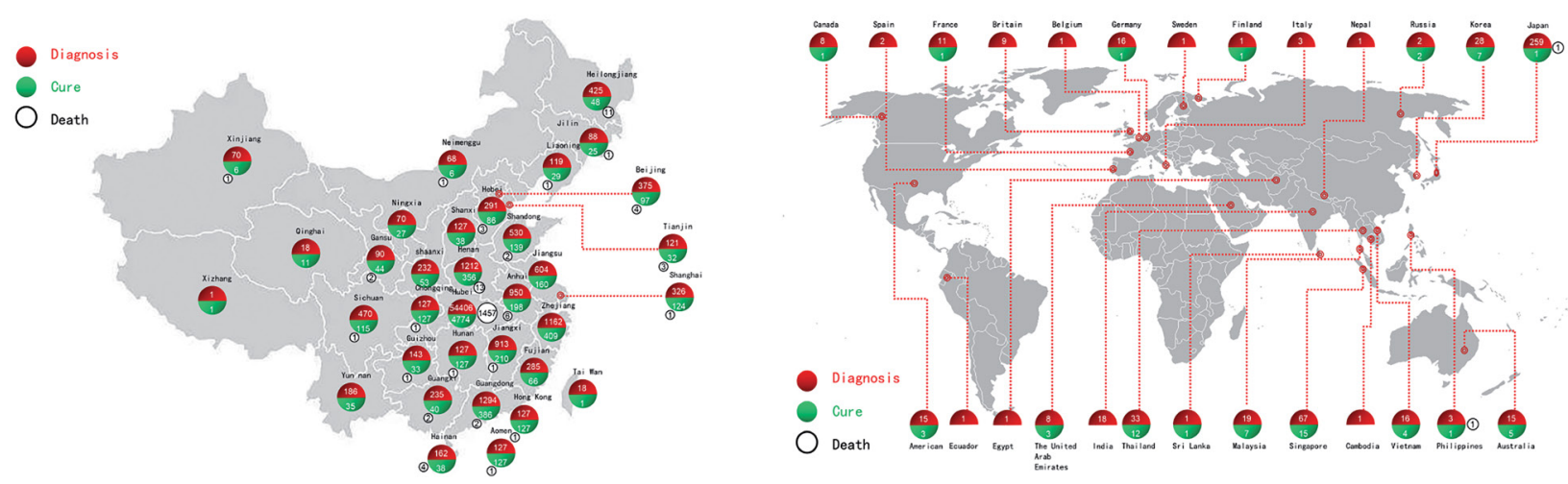

Fig. 1

Geographic distribution of diagnoses, cures, and deaths from COVID-19 as of 15 February 2020 
Table 2. Demographics and clinical symptoms of COVID-19 patients at presentation in six different studies

\begin{tabular}{|c|c|c|c|c|c|}
\hline Study \# & Huang et al. (2020) & Chen et al. (2020) & Wang et al. (2020) & Guan et al. (2020) & DeChang etal.(2020) \\
\hline \multicolumn{6}{|l|}{ Demographics } \\
\hline Patients, $\mathrm{n}$ & 41 & 99 & 138 & 1099 & 13 \\
\hline Age, mean(range) & $49.0(41.0-58.0)$ & $55.5(21-82)$ & $56(42-68)$ & $47.0(34.0-57.0)$ & $34(34-48)$ \\
\hline Men, $n(\%)$ & $30(73 \%)$ & $67(68 \%)$ & $75(54.3 \%)$ & $640(58.2 \%)$ & $10(76.9 \%)$ \\
\hline Women, $\mathrm{n}(\%)$ & $11(27 \%)$ & $32(32 \%)$ & $63(45.7 \%)$ & $459(41.8 \%)$ & $3(23.1 \%)$ \\
\hline \multicolumn{6}{|l|}{ Symptoms n (\%) } \\
\hline Fever & $40(98 \%)$ & $82(83 \%)$ & $136(98.6 \%)$ & $437(43.1 \%)$ & $12(92.3 \%)$ \\
\hline Cough & $31(76 \%)$ & $81(82 \%)$ & $82(59.4 \%)$ & $744(67.7 \%)$ & $6(46.2 \%)$ \\
\hline Breathlessness & $22 / 40(55 \%)$ & $31(31 \%)$ & $43(31.2 \%)$ & $204(18.6 \%)$ & $1(7.7 \%)$ \\
\hline Diarrhoea & $1(3 \%)$ & $2(2 \%)$ & $14(10.1 \%)$ & $41(3.7 \%)$ & $1(7.7 \%)$ \\
\hline Myalgia & & $11(11 \%)$ & $48(34.8 \%)$ & $163(14.8 \%)$ & \\
\hline Fatigue & $18(44 \%)$ & & & $419(38.1 \%)$ & \\
\hline Sputum production & $11(28 \%)$ & & & $367(33.4 \%)$ & \\
\hline Headache & $3(8 \%)$ & $8(8 \%)$ & $9(6.5 \%)$ & $150(13.6 \%)$ & \\
\hline Haemoptysis & $2(5 \%)$ & & & $10(0.9 \%)$ & \\
\hline Sore throat & & $5(5 \%)$ & $24(17.4 \%)$ & $153(13.9 \%)$ & \\
\hline Chest pain & & $2(2 \%)$ & & & \\
\hline Vomiting & & $1(1 \%)$ & $5(3.6 \%)$ & $55(5.0 \%)$ & \\
\hline Nausea & & $1(1 \%)$ & $14(10.1 \%)$ & $55(5.0 \%)$ & \\
\hline Confusion & & $9(9 \%)$ & $13(9.4 \%)$ & & \\
\hline Anorexia & & & 55 (39.9\%) & & \\
\hline Expectoration & & & $37(26.8 \%)$ & & \\
\hline Abdominal pain & & & $3(2.2 \%)$ & & \\
\hline Conjunctival congestion & & & & $9(0.8 \%)$ & \\
\hline Nasal congestion & & & & $53(4.8 \%)$ & \\
\hline Chill & & & & $125(11.4 \%)$ & \\
\hline Throat congestion & & & & $19(1.7 \%)$ & \\
\hline Tonsil swelling & & & & $23(2.1 \%)$ & \\
\hline Enlargement of lymph nodes & & & & $2(0.2 \%)$ & \\
\hline Rash & & & & $2(0.2 \%)$ & \\
\hline Rhinorrhea & & & & & $1(7.7 \%)$ \\
\hline Upper airway congestion & & & & & $8(61.5 \%)$ \\
\hline
\end{tabular}

the number of confirmed cases continues to rise, newly infected patients do not have access to hospitals in Wuhan. Although the data are incomplete, there are 14,046 occupied beds in 35 designated hospitals in Wuhan, and these are mainly for the treatment of patients with severe, critical, and suspected critical conditions. In addition, 15 military compounds (11,600 beds) were set up for the treatment and isolation of less severely ill patients and 17 university dormitories ( 11,455 beds) were acquired and renovated to serve as a centralized isolation place for people who had contact with patients.

Somewhat reassuringly, the latest reports from Hubei and other provinces show that the number of new cases has begun to decline. However, many factors that influence the outbreak's future evolution remain unknown. The COVID-19 outbreak in China has not peaked, and the turning point has not yet been achieved. Many of the con- firmed patients had never been to Wuhan and apparently had no contact with COVID-19 patients, making it difficult to diagnose and screen patients with atypical symptoms. A study by Guan et al. (2020) that examined 1199 patients in 31 provinces found that human-to-human transmission was an important feature of COVID-19 pneumonia, and that the median incubation period was 3 days (range 0 to 24 days). In addition, there appears to be a potential for fecal-oral transmission, and SARS-CoV-2 was detected in stool samples from patients with abdominal symptoms (Chan et al., 2020b; Phan et al., 2020; Zhang et al., 2020). Because of the increasing numbers of international cases caused by travelers from China, many countries, including the United States, Singapore, Australia, have taken emergency measures to regulate international flights, restrict the entry of Chinese citizens, and even evacuate their residents from China. 


\section{Clinical features}

With the increasing number of patients diagnosed with COVID-19, several published studies have characterized the demographics and clinical features of these patients (Table 2). There was a report that treatment with intravenous remdesivir (a novel nucleotide analogue prodrug currently in the development in the United States) had a significant effect (Holshue et al., 2020; Sheahan et al., 2020). But this was a case study, and clinical studies are therefore required for confirmation. Most patients receive antiviral and antibacterial therapy, and patients with severe disease receive systemic corticosteroids. However, the clinical benefit appears to be limited, and many patients continue to deteriorate (Wang et al., 2020). The median duration from the onset of the first symptoms of dyspnea to hospital admission is 5 days, and to ARDS is 7 days. A total of $5.00 \%$ of patients are admitted to an ICU, $2.18 \%$ require invasive ventilation, and $1.36 \%$ die (Guan et al., 2020).

\section{Diagnosis}

There were initially no reliable laboratory tests for the diagnosis of COVID-19. However, based on early findings in hospitals, the National Health Commission of China has updated and issued the sixth edition of diagnostic criteria, and redefined the case definitions for suspected and confirmed cases (http://news.hbtv.com.cn/p/1787740.html). Suspected case (any single criterion):

- history of travel or residence in Wuhan and surrounding areas or other communities that had case reports within 14 days before symptom onset

- history of contact with new coronavirus-infected nucleic acid-positive persons within 14 days before symptom onset

- fever or respiratory symptoms and presence in Wuhan or surrounding areas or other communities that had case reports within 14 days before symptom onset

- presence in a region that had clustering of cases.

Confirmed case (any single criterion):

- fluorescence RT-PCR positivity for SARS-CoV-2

- viral gene sequence with high similarity to SARS-CoV-2

\section{The Coronaviridae family}

The newly discovered SARS-CoV-2 belongs to the Coronaviridae family and the Betacoronavirus genus. It has a spindle or oblong shape with pleomorphism, a diameter of 60 to $140 \mathrm{~nm}$, is enclosed by an envelope, and has a positive-sense single-stranded RNA genome. Similar to SARS-CoV and MERS-CoV, the SARS-CoV-2 genome encodes non-structural proteins (e.g., 3-chymotrypsinlike protease, papain-like protease, helicase, and RNAdependent RNA polymerase), structural proteins (e.g., spike glycoprotein), and accessory proteins. However, there are distinctive genetic differences between SARSCoV-2 and other coronaviruses. For example, SARS-CoV-2 has a homology of up to $85 \%$ with SL-CoVZC45, isolated from bats (Chan et al., 2020a).

The Coronaviridae family has two genera: Coronavirus (serogroups I, II, and III) and Torovirus. Both genera have species that are human pathogens, and researchers have isolated numerous biologically distinct avian and mammalian coronaviruses (Knudsen et al., 2003). SARS-CoV-2 has $88 \%$ identity with two bat-derived SARS-like coronaviruses (SL-CoVZC45 and SL-CoVZXC21) that were collected during 2018 in Zhoushan (eastern China)(Lu et al., 2020). As typical RNA viruses, the average rate of coronavirus evolution is roughly $10^{-4}$ nucleotide substitutions per site per year (Luk et al., 2019). There is scientific evidence that SARS-CoV-2 originated from one source within a very short period of time and was detected relatively rapidly. However, because the virus is transmissible among humans, constant surveillance for new mutations is needed (Su et al., 2016).

\section{Targets for intervention}

At present, existing antiviral drugs appear to have limited effects on SARS-CoV-2, and there is no specific drug or vaccine approved for the treatment of any of the human coronavirus diseases. Several possible approaches can be envisaged to control or prevent new infections of SARS-CoV-2, including vaccines, monoclonal antibodies, oligonucleotide-based therapies, peptides, interferon therapy, and small molecule drugs. The different isolates of SARS-CoV-2 have differences in sequence, mostly single nucleotide variations. In particular, there are changes in amino acids 62 and 84 of ORF8, a polypeptide implicated in driving the coronavirus transition from bats to humans (Lau et al., 2015). Some studies found that SARS-CoV-2 is actively acquiring new mutations that may enable it to escape antiviral drugs; if so, this raises a serious challenge to the development of conventional drugs and vaccines (Nguyen et al., 2020). Some researchers reported that SARS-CoV-2, similar to severe acute respiratory syndrome SARS-CoV, belongs to the lineage B of Betacoronavirus and has the ability to utilize human angiotensin-converting enzyme 2 (ACE2) as a receptor to infect human cells (Zhou et al., 2020). The SARS-CoV-2 spike protein subunit S2 seems to play a key role in mediating virus fusion and 
entry into the host cell. In this process, heptad repeat 1 (HR1) and heptad repeat 2 (HR2) interact to form a sixhelical bundle (6-HB), thereby bringing viral and cellular membranes into close proximity for fusion, suggesting that these proteins could be therapeutic targets (Xia et al., 2020).

\section{Perspectives}

As the number of confirmed cases of COVID-19 continues to rise, the situation in China remains serious. We cannot yet predict the success of sustained efforts to contain and eradicate SARS-CoV-2. Given the urgency of the outbreak, some clinical studies have begun using existing antiviral drugs, such as remdesivir and ribavirin, based on our knowledge of coronaviruses. Although our data may be incomplete, there are currently more than 80 clinical studies examining SARS-CoV-2, and scientists from all over the world are working on early development of vaccines. The existing body of knowledge on coronaviruses presents scientists with a multitude of potential targets for medical interventions. In addition, the strategy for containment outlined by the WHO has proven to be effective in industrialized countries and developing countries.

The coronaviruses have numerous potential targets for possible medical interventions. In addition, the prevention and control strategies of the WHO have proven to be effective worldwide. The most serious question is whether COVID-19 has reached an uncontrollable level in China. Coronaviruses have evolved since the SARS epidemic of 17 years ago, and they continue to threaten human health and even pose a major threat to international public health, especially in densely populated countries with poor infrastructures and in areas with immunocompromised populations. However, we believe that the efforts of many scientists will accelerate the pace of controlling this epidemic.

\section{Actualization of the situation}

Since the outbreak of the epidemic, China has taken active prevention and control measures and achieved good results. The epidemic has been largely contained, with zero increases in confirmed cases in many areas of China. But recently the epidemic situation in other countries has begun to develop into an uncontrollable situation. On February 29, the "China-WHO NCP (COVID-19) Joint Inspection Report" stated that almost everyone is susceptible to COVID-19, and on March 11, the WHO declared the SARS-CoV-2 outbreak as pandemic. According to the latest data from Johns Hopkins university, there were 735,457 confirmed COVID-19 cases and 34,582 deaths worldwide and it has reached 193 countries. Affected by COVID-19, the global economy has fallen sharply and mankind is facing unprecedented challenges. At this critical moment, only with the nations of the world united to fight the virus, mankind can overcome this pandemic.

Acknowledgments. This project was supported by the Medjaden Academy \& Research Foundation for Young Scientists (Grant No.MJA nCoV_MJA20200224) and the Free innovation pre-research fund and platform scientific research fund in 2019 (02.03.2019-111).

\section{References}

Chan JF, Kok KH, Zhu Z, Chu H, To KK, Yuan S, Yuen KY., Emerg. Microbes Infect. 9, 221-236, 2020. https://doi.org/10.10 80/22221751.2020.1719902

Chan JF, Yuan S, Kok KH, To KK, Chu H, Yang J, Xing F, Liu J, Yip CC, Poon RW, Tsoi HW, Lo SK, Chan KH, Poon VK, Chan WM, Ip JD, Cai JP, Cheng VC, Chen H, Hui CK, Yuen KY., Lancet 395, 514-523, 2020b. https://doi.org/10.1016/ S0140-6736(20)30154-9

Guan W, Ni Z, Hu Y. et al., New Engl. J. Med., 2020. https://doi. org/10.1056/NEJMoa2002032

Guo Q, Li M, Wang C, Wang P, Fang Z, Tan J, Wu S, Xiao Y, Zhu H., bioRxiv, 2020.01.21.914044, 2020.

Holshue ML, DeBolt C, Lindquist S, Lofy KH, Wiesman J, Bruce H, Spitters C, Ericson K, Wilkerson S, Tural A, Diaz G, Cohn A, Fox L, Patel A, Gerber SI, Kim L, Tong S, Lu X, Lindstrom S, Pallansch MA, Weldon WC, Biggs HM, Uyeki TM, Pillai SK., N. Engl. J. Med. 382, 929-936, 2020. https://doi.org/10.1056/NEJMoa2001191

Huang C, Wang Y, Li X, Ren L, Zhao J, Hu Y, Zhang L, Fan G, Xu J, Gu X, Cheng Z, Yu T, Xia J, Wei Y, Wu W, Xie X, Yin W, Li H, Liu M, Xiao Y, Gao H, Guo L, Xie J, Wang G, Jiang R, Gao Z, Jin Q, Wang J, Cao B., Lancet 395, 497-506, 2020. https://doi.org/10.1016/S0140-6736(20)30183-5

Ji W, Wang W, Zhao X, Zai J, Li X., J. Med. Virol. 92, 433-440, 2020. https://doi.org/10.1002/jmv.25682

Knudsen TB, Kledal TN, Andersen O, Eugen-Olsen J, Kristiansen TB., Scand. J. Immunol. 58, 277-284, 2003. https://doi. org/10.1046/j.1365-3083.2003.01302.x

Lau SK, Feng Y, Chen H, Luk HK, Yang WH, Li KS, Zhang YZ, Huang Y, Song ZZ, Chow WN, Fan RY, Ahmed SS, Yeung HC, Lam CS, Cai JP, Wong SS, Chan JF, Yuen KY, Zhang HL, Woo PC., J. Virol. 89, 10532-10547, 2015. https://doi. org/10.1128/JVI.01048-15

Lu R, Zhao X, Li J, Niu P, Yang B, Wu H, Wang W, Song H, Huang B, Zhu N, Bi Y, Ma X, Zhan F, Wang L, Hu T, Zhou H, Hu Z, Zhou W, Zhao L, Chen J, Meng Y, Wang J, Lin Y, Yuan J, Xie Z, Ma J, Liu WJ, Wang D, Xu W, Holmes EC, Gao GF, Wu G, Chen W, Shi W, Tan W., Lancet 395, 565-574, 2020. https://doi.org/10.1016/S0140-6736(20)30251-8 
Luk H, Li X, Fung J, Lau S, Woo P., Infect. Genet. Evol. 71, 21-30, 2019. https://doi.org/10.1016/j.meegid.2019.03.001

Nguyen TM, Zhang Y, Pandolfi PP., Cell Res. 30, 189-190, 2020. https://doi.org/10.1038/s41422-020-0290-0

Phan LT, Nguyen TV, Luong QC, Nguyen TV, Nguyen HT, Le HQ, Nguyen TT, Cao TM, Pham QD., N. Engl. J. Med. 382, 872-874,2020. https://doi.org/10.1056/NEJMc2001272

Pradhan P, Pandey AK, Mishra A, Gupta P, Tripathi PK, Menon MB, Gomes J, Vivekanandan P, Kundu B., bioRxiv, 2020.01.30.927871, 2020.

Sheahan TP, Sims AC, Leist SR, Schafer A, Won J, Brown AJ, Montgomery SA, Hogg A, Babusis D, Clarke MO, Spahn JE, Bauer L, Sellers S, Porter D, Feng JY, Cihlar T, Jordan R, Denison MR, Baric RS., Nat. Commun. 11, 222, 2020. https://doi.org/10.1038/s41467-019-13940-6

Su S, Wong G, Shi W, Liu J, Lai A, Zhou J, Liu W, Bi Y, Gao GF., Trends Microbiol. 24, 490-502, 2016. https://doi. org/10.1016/j.tim.2016.03.003

Wang D, Hu B, Hu C, Zhu F, Liu X, Zhang J, Wang B, Xiang H, Cheng Z, Xiong Y, Zhao Y, Li Y, Wang X, Peng Z., JAMA, 2020. https://doi.org/10.1001/jama.2020.1585
WHO Statement on the second meeting of the international Health Regulations (2005): Emergency Committee regarding the outbreak of novel coronavirus (2019nCoV), 2020. at https://www.who.int/news-room/ detail/30-01-2020-statement-on-the-second-meetingof-the-international-health-regulations-(2005)-emergency-committee-regarding-the-outbreak-of-novelcoronavirus-(2019-ncov).).

Xia S, Zhu Y, Liu M, Lan Q, Xu W, Wu Y, Ying T, Liu S, Shi Z, Jiang S, Lu L.,Cell Mol.Immunol.,2020.https://doi.org/10.1038/ s41423-020-0374-2

Zhang H, Kang Z, Gong H, Xu D, Wang J, Li Z, Ciu X, Xiao J, Meng T, Zhou W, Liu J, Xu H., 2020. doi. org/10.1101/2020.01.30.927806

Zhou P, Yang XL, Wang XG, Hu B, Zhang L, Zhang W, Si HR, Zhu Y, Li B, Huang X, Zheng XS, Zhao K, Chen QJ, Deng F, Liu LL, Yan B, Zhan FX, Wang YY, Xiao GF, Shi ZL., Nature 579, 270-273, 2020. https://doi.org/10.1038/ s41586-020-2012-7

Zhu N, Zhang D, Wang W, Li X, Yang B, Song J, Zhao X, Huang B, Shi W, Lu R, Niu P, Zhan F, Ma X, Wang D, Xu W, Wu G, Gao G F, Tan W., N. Engl. J. Med. 382, 727-733, 2020. https://doi.org/10.1056/NEJMoa2001017 